compare the effect of milk or water before alcohol with alcohol alone.

So far the weight of evidence remains in favour of milk delaying the absorption of alcohol. But the practical value of these studies is doubtful, for people who drink and drive without regard to the hazard are unlikely to adopt a habit which to many will be inconvenient and unpalatable. Furthermore, a procedure which reduces the level of alcohol in the blood will reduce its effect, and this might encourage further drinking to achieve the desired effect.

This last objection might be overcome by a procedure which does not reduce the peak level of alcohol but does increase the rate of fall from the peak. Thus a person could enjoy his drink but a short time later be safe to drive. Alcohol in beer or sweet wine is metabolized more rapidly than alcohol in water made up to the same concentration and volume. ${ }^{3}$ This has been attributed to the carbohydrate content of those drinks. Ingestion of sucrose or fructose with alcohol has a similar effect, ${ }^{7}$ though it has been said that this effect is probably too slight to have any clinical or medicolegal significance. However, investigators at the Edinburgh Regional Poisoning Treatment Centre ${ }^{8}$ have shown in a controlled trial of the treatment of patients with acute alcoholic intoxication that an intravenous infusion of $200 \mathrm{~g}$ of frutose increases the rate of fall of blood alcohol levels by approximately $25 \%$. Some of the patients complained of upper abdominal pain, burning, and nausea, and though the procedure may be useful in disclosing signs of co-existent head injury, drug overdose, or other acute medical emergency, or for shortening the inebriate's sojourn in the casualty department, it is not a practical proposition in the saloon bar.

Even if a technique became available that significantly reduced blood levels of alcohol and was acceptable to the drinker, it should not be allowed to detract from efforts to tell the drinking driver that alcohol impairs his judgement. Nor should it be allowed to support ideas that the limit set by the 1967 Act can safely be raised.

${ }^{1}$ Medical Research Committee, Special Report Series, No. 31. London, H.M.S.O., 1919 .

2 Southgate, H. W., and Carter, G., British Medical fournal, 1926. 1, 463.

3 Haggard, H. W., Greenberg, L. A., and Lolli, G., Quarterly fournal of Studies on Alcohol, 1941, A., and 684 .

4 Miller, D. S., Stirling, J. L., and Yudkin, J., Nature, 1966, 212, 1051.

5 Meckett, A. H., Mitchard, M., and Saunders, A., Autocar, 1971, 135, 34.

- Janus, E. D., and Sharman, J. R., New Zealand Medical fournal, 1972, 75,339

7 Wallgren, H., and Barry, H., Actions of Alcohol, 1. Amsterdam, Elsevier,

8 Brown, S. S., Forrest, J. A. H., and Roscoe, P., Lancet, 1972, 2, 898.

\section{Virus and Bacteria in Influenza}

The lethal effeot of influenza on old people is mainly from its pulmonary complications. Though a disproportionate mortality among younger adults was notable in the 1918 pandemic, the virus which caused it was probably more pneumotropic than those causing epidemics before or since. ${ }^{1}$ Deaths from pneumonia in the 1918 epidemic were generally associated with superinfection by Haemophilus influenzae and to a less extent $\beta$-haemolytic streptococci, ${ }^{2}$ whereas deaths from pneumonia associated with Asian strains of influenza have most frequently been due to pyogenic staphylococci and to a less extent pneumococci and $H$. influenzae. . $^{3-5}$ Though in comparison with the 1918 virus the pneu- motropism of the Asian strains of influenza is low, it may be enhanced in old people and in patients with chronic lung and heart disease, particularly rheumatic heart disease. ${ }^{3-6}$ Pregnancy also predisposes to pulmonary complications, particularly if rheumatic heart disease is present. But in some $\underset{\mathbb{D}}{\mathrm{C}}$ cases no bacterial pathogens can be isolated, and this lack, $C$ together with evidence from histological studies, suggests that a virus pneumonia itself without bacterial superinfection $\stackrel{5}{?}$ can cause death. 457

Though influenza is often common among children, studies $\frac{\overline{\bar{N}}}{\bar{N}}$ on children admitted to hospital with an infection of the $\overrightarrow{\widehat{D}}$ lower respiratory tract show influenza to be a rare cause of it. A longitudinal survey on the aetiology of acute respiratory ${ }^{\circ}$ infections conducted over 13 years in Newcastle upon Tyne confirmed this, even though, for example, the Hong Kong $\vec{\omega}$ variant of Asian influenza was prevalent in the north of Eng- $\stackrel{\sim}{\vec{D}}$ land during the winters of $1968-9$ and 1969-70. In view of $\frac{5}{3}$ this it was somewhat surprising that, of 61 children with influenza admitted to a hospital in Newcastle last winter, $\circ$ most being aged 3 years or less, $42 \%$ had evidence of lower $\vec{\omega}$ respiratory tract infection. ${ }^{8}$ It was most severe in those with chronic or congenital disease. Despite an epidemic among ${ }^{5}$ young children, influenza was not prevalent in older persons 9 in Newcastle last winter, perhaps because they had pre- $\omega$ viously been infected with the Hong Kong strain between 1968 to 1970 and only the very young remained susceptible.

Both influenzal and meningococcal infections often occur $\frac{3}{9}$ separately in winter, and therefore not surprisingly the nature $\stackrel{\mathbb{D}}{\sim}$ of their association together in some cases has been ques- $\vec{\omega}$ tioned. Until lately it was generally considered coinciden- N tal.9-11 But two recent reports suggest that their association 0 may be closer than hitherto supposed. In a serological study of meningococcal and influenzal infection in U.S. air force personnel T. C. Eickhoff ${ }^{12}$ showed that meningococcal \% colonization was more than five times commoner in patients $\stackrel{D}{\stackrel{D}{2}}$ who had concurrent evidence of Hong Kong influenza than $\overrightarrow{0}$ in those who did not, but none developed systemic infection 3 with the meningococcus. More recently L. S. Young and colleagues $^{13}$ in Mississippi described a simultaneous outbreak of infection due to group B sulphonamide-resistant meningococci and influenza among 55 elderly women in a mental institution. Half the patients had influenza, 11 developed $\frac{5}{3}$ systemic meningococcal disease, and 3 died. There was no correlation between systemic meningococcal infection and $\stackrel{\rho}{\xi}$ concurrent influenza. But there was a correlation between serological evidence of influenza and the meningococcal carrier state, for $17 \%$ of patients with serological evidence $\stackrel{\circ}{\rightarrow}$ of influenza were meningococcal carriers, whereas there were $\frac{7}{0}$ no carriers among those without serological evidence of influenza.

What might be the nature of the association between these $\frac{\omega}{\sigma}$ two infections? Young and his colleagues considered three hypotheses. The first was that influenza predisposed to the development of systemic infection among meningococcal $\stackrel{\odot}{?}$ carriers. This they considered unlikely because in their study $T$ a number of cases of systemic disease occurred among $\frac{+}{\oplus}$ patients without influenza. The high case-to-carrier ratio in ? the epidemic could have been due to the virulence of the $\stackrel{D}{\circ}$ meningococcus or alteration in host susceptibility unrelated to influenza. Secondly, infection by influenza virus could 8 have resulted in widespread dissemination of meningococci, since both infections are transmitted by droplets. However, the overall carrier rate in this study was too low to support? this. The final and most tenable hypothesis suggested was that influenza might alter certain host factors, thereby en- 
hancing meningococcal colonization after exposure to these bacteria rather than meningococcal disease itself. The concept that viruses may have a role in conditioning the host to colonization rather than to disease, as occurs with influenza and its pulmonary bacterial complications, deserves careful study.

1 Ciba Foundation Study Group, Virus Virulence and Pathogenicity, ed. G. E. Wolstenholme and M. O'Connor, p. 43. London, Churchill, 1960 .

2 Wolbach, S. B., and Frothingham, C., Archives of Internal Medicine, 1923, 32, 571 .

3 British Medical fournal, 1958, 1, 915.

Hers, J. F. P., Masurel, N., and Mulder, J., Lancet, 1958, 2, 1141.

5 Lers, J. F. P., Masurel, N., and Mulder, J., Lancet, 1958, 2, 1141 . Rogers, D. E., Fournal of Clinical Investigation, 1959, 38, 213.

Assaad, F. A., and Reid, D., Bulletin of the World Health Organization, $1971,45,113$.

Lindsay, M. I., Hermann, E. C., Morrow, G. W., and Brown, A. L., fournal of the American Medical Association, 1970, 214, 1825.

Brocklebank, J. T., Court, S. D. M., McQuillin, J., and Gardner, P. S., Lancet, 1972, 2, 497.

${ }^{9}$ Rolleston, H., Lancet, 1919, 1, 541.

10 Hedrich, A. W., Public Health Report, 1931, 46, 2709.

11 Lal, H. B., Narayan, T. K., Kalra, S. L., and Lal, R., fournal of the Indian Medical Association, 1963, 40, 113.

12 Eickhoff, T. C., Fournal of Infectious Diseases, 1971, 123, 519. J. V., New England $¥$ ournal of Medicine, 1972, 287, 5.

\section{Hazardous Wastes}

Balancing the beneficial effect of a remedy against its undesirable side effects is a commonplace in therapeutics. Industry has similar problems in disposing of its wastes. These can be regarded as the unfortunate but largely inevitable side effects of processes which are indispensable to the needs of modern life.

If there was a time when a high chimney or the shortest route to the nearest hole or river afforded immediate relief to problems of disposal, it must be admitted that it has gone for ever. Its departure has been hastened by a number of factors, the most important being an increasing body of legislation combating indiscriminate disposal and particularly directed towards preventing contamination of the atmosphere or water supplies. Until recently surface disposal of waste was not so well controlled, but shared in the more responsible attitudes of most of industry to the general problems of pollution. Most of this improvement admittedly stemmed from self-interest. Only the most improvident manufacturer is likely in these trying times to be discarding materials which could be economically reclaimed and re-used by himself or sold elsewhere. Additionally, the larger industrial organizations are at present so sensitive about their public image that they generally lead, rather than are coerced into, moasures to avoid despoiling the environment. Nevertheless, $90 \%$ of British industry lies outside the scope of these large organizations, and, though smallness in no way equates with irresponsibility, the resources and techniques for proper handling of waste are often simply not available. Small amounts of residue make reclamation not worth while, and if discharge is prohibited then the waste is most often passed to a contractor for removal and disposal.

Many contractors have developed a high degree of scientific and technical competence. By close liaison with their clients they build up a knowledge of industrial processes (often commercially secret) which enables them to anticipate handling and disposal difficulties. Some also possess the analytical facilities to identify wastes of unknown composition before deciding which treatment to adopt. Many materials present unique problems in their disposal, and in all cases transport and handling charges will be considerable. Though only a small proportion of all waste will be toxic this risk must be assessed and the workers protected during handling, transport, treatment, and disposal. Two cases mentioned in the latest report from the Chief Inspector of Factories ${ }^{1}$ illustrate the latter point. One was of unusually acute mercury intoxication and the other a fatal case of cyanide poisoning. Both occurred during reclamation or treatment of waste.

Ultimately most waste will be disposed of by deposition on either land or sea. Land is the more likely, and the selection of suitable areas requires considerable care. Such factors as accessibility to trespass, impermeability or absorption characteristics of soil, height of water table, and lie of surrounding water courses must all be assessed. Public feeling may also be stirred by the proximity of such an area. None of this competence and equipment can be provided cheaply, and the cost provides another disincentive to the small industry. The producer of waste at this level will be tempted to seek the cheapest tender for disposal. The stage is then set for the entry of the villain-the "cowboy-contractor"whose operations have in some cases led to spectacular abuses of acceptable practice.

The Deposit of Poisonous Waste $\mathrm{Act}^{2}$ received royal assent in March of this year. It has two main features. It becomes an offence to deposit on land any poisonous, noxious, or polluting waste which subsequently might cause danger to persons or animals or pollute any water supply. Secondly, it prescribes a system of notification whereby persons disposing of such waste are required to give local authorities advance information about the nature and quantities of the wastes deposited in their area. Similarly, before removal of waste, carriers must satisfy themselves that the required notices have been supplied and they must be given a copy of the notice. The tip operator must also have received a notice in advance, and he must notify the relevant authorities once the deposit has been made. The penalties for failure to observe these requirements are severe and can be imposed on individuals within a firm as well as on the employing organization. A general practitioner who discards his timeexpired drugs in the domestic dust-bin is possibly more at risk of penalty than a large hospital, which may be exempt as Crown property.

These restrictions certainly represent an important addition to the control of pollution, for experience has regrettably shown that reliance on voluntary restraint is likely to be disappointing. The Act is intended to arm the appropriate authorities, but unfortunately there is considerable doubt about who is actually responsible for seeing that it is followed. The imminent reorganization of local government confuses identification of the proper authority. The rationalization of water boards proposed in the Queen's Speech may also discourage the existing bodies from devoting much attention to waste disposal before they are swallowed up in larger areas.

Another well-founded criticism of the Act is that it once again leaves the small industry or authority in the worst possible position, for it gives instructions on what not to do but lacks practical advice on alternatives. The proper treatment of toxic wastes can be expensive, and though the slogan "the polluter must pay" is fine in principle there is not much doubt that eventually it is the public who bear this cost, whether as consumers or ratepayers. There is therefore a strong case for the public purse to be employed to better 